\title{
El Poder en 1820: la Junta Provisional y el Gobierno
}

\author{
BLANCA Esther BuLdain JaCA
}

El período de transición política que se inició el 7 de marzo de 1820 con la promesa de Fernando VII de jurar la Constitución de Cádiz y se cerró con la solemne reunión de las Cortes el 9 de julio del mismo año, ofrece, entre otras, la singular caracteristica del ejercicio del poder ejecutivo. Según las leyes, esta facultad correspondía exclusivamente al Rey auxiliado por un Gobierno cuyos Ministros podía designar o destituir libremente. Mientras en la primera etapa liberal (1810-1814) la figura del Rey fue sustituida por las sucesivas Regencias que ejercieron el poder en su nombre, junto a unas Cortes que en muchos casos se abrogaron facultades del ejecutivo, en 1820 se le sumió a Fernando VII en una cautividad, no ya física como la impuesta por Napoleón, sino moral. La triunfante revolución le obligó a crear el 9 de marzo una Junta Provisional a la que el Gobierno debía consultar todas las medidas y publicarlas con su acuerdo ${ }^{1}$. De esta forma el papel del Rey, tan amplio en teoría, quedó en la práctica tan reducido a la nada que ni siquiera pudo nombrar a sus Ministros, limitándole de hecho a dar su real asentimiento a cuantas propuestas le presentaron.

Si el Rey desempeñó el papel más desagradable en la cúpula del poder, al Gobierno, cualquiera de los tres que hubo, le tocó jugar el más deslucido. Aunque por la Constitución los Ministros eran responsables de las decisiones que adoptasen en su respectiva Secretaría del Despacho, sin embargo, carecieron casi por completo de autoridad. Su competencia quedó reducida, de hecho, a consultar a la Junta cualquier asunto y a

1 Real decreto de 9 de marzo para la creación de la Junta Provisional. ARCHIVO DEL CONGRESO, Papeles reservados de Fernando VII, (citado en adelante con las siglas A.C.), t. 36, 149-150; t. 35, 1 y 1v., sesión única del 9 de marzo. Gaceta Extraordinaria, 9 marzo 1820, n. 34,251 . Sobre la instalación de la Junta Provisional y su poder real véase mi artículo La Junta Provisional de 1820: instalación y atribuciones en Revista de Historia Contemporánea. Sevilla, 1982, n.1, 39-64. 
cumplir sus resoluciones. Sólo tuvieron libertad de actuación en cuestiones de trámite y en la preparación de los trabajos para las futuras Cortes.

De esta forma, la Junta se constituyó en una institución tutelar no sólo para el Rey, sino para el Gobierno, e incluso para el Gobierno constitucional elegido por ella misma. Hasta tal punto es cierto que la incorporación de los nuevos Ministros en nada varió el sistema de consultas establecido y el cumplimiento fiel de las opiniones de la Junta, que se hace necesario observar la fecha y firma de los documentos para saber quién era el Ministro en cada momento. El testimonio del Ministro de la Guerra, Marqués de las Amarillas, no deja lugar a dudas sobre las superioridad del poder de la Junta cuando afirmó: “... ella, y no S.M. fue el verdadero soberano de España, puesto que había jurado no sólo gobernar con su acuerdo, sino no hacer nada contra su parecer" ?.

La única fuente que ilustra de forma fidedigna la dinámica y calidad de estas relaciones en la cumbre es la documentación, rica y abundante por otra parte, cruzada entre la Junta y los Ministros. Los Recuerdos del Marqués de las Amarillas, con ser una fuente historiográfica interesante para el tema que nos ocupa, carecen de la objetividad y diversidad que las fuentes primarias proporcionan. Aunque la Gaceta de Madrid dejó traslucir en algunos momentos muy significativos las tensiones existentes, como cuando se derogó algún decreto recién promulgado, en general aquéllas no tiascendieron a la opinión pública.

Como era de esperar, las relaciones entre la Junta y el Gobierno heredado del-Antiguo Régimen no pudieron ser cordiales. Los choques y tensiones fueron frecuentes y se vieron, además, agudizados porque precisamente en los inicios del período era cuando se tenía que poner en vigor toda la reforma realizada por las Cortes de Cádiz. Fácil es suponer, por otra parte, hacia qué régimen se inclinaba su fidelidad.

Aunque en un primer momento la Junta elaboró tres minutas de decreto para "inspirar a toda la Monarquía una justa confianza en el Gobierno" 3 , desde el principio se supo también que gobernar el país con el antiguo Ministerio era inviable. Pronto la Junta comenzó a pedir el relevo con discreción y verbalmente para acabar haciéndolo por escrito y enérgicamen-

\footnotetext{
${ }^{2}$ Pedro Agustín Girón (Marqués de las Amarillas), Recuerdos (1778-1837), Pamplona, EUNSA, 1979, t. II, 98.

${ }^{3}$ Estas minutas se referian a la separación de la Tesorería General del Crédito Público, al restablecimiento de los Ministerios de la Gobernación de la Península y de Ultramar y de las Juntas de censura como en 1814 para que se lievase a cabo la libertad de imprenta, así como una proclama de la Junta sobre este mismo tema. A.C., t. 36, 160-162,; t. 35, 6-7, $7 \mathrm{v}$. y 8 , sesiones de mañana y tarde del 10 de marzo.
} 
te. Y ello no sólo debido al propio convencimiento sino también a la presión que en el mismo sentido ejercía desde diversos ángulos la opinión pública ${ }^{4}$. Así, la Junta de Galicia en su primera exposición a la Provisional pedía que "S.M. separe de su lado a todos los funcionarios que perdieron la confianza pública" 5 . Varios ciudadanos de Madrid enviaron también en los primeros días una exposición a la Junta pidiendo concretamente la destitución de los Ministros de Estado, Guerra, Hacienda, y Marina ${ }^{6}$. Ya en el mes de abril, las sociedades patrióticas de Lorencini y San Sebastián "recomendaban" a la Junta la separación del Gobierno de "quienes han servido para esclavizar" ". La necesidad de relevar el antiguo Gabinete fue ineludible, a pesar del reconocimiento por parte de la Junta de la buena fe de algunos Ministros y de su esfuerzo por restablecer cuanto antes el nuevo sistema e, incluso, por anticiparse con la intención, quizás, de permanecer en el cargo ${ }^{8}$.

La distorsión de los deseos de la Junta por parte del Gabinete, obligó a ésta a tomar el acuerdo, para nosotros hoy afortunado, de que todas las comunicaciones con el Gobierno fueran por escrito, terminando definitivamente las comisiones verbales de la Junta a los Ministros, de tal forma que no se volvió a la antigua costumbre ni con el nombramiento del Ministerio constitucional ${ }^{9}$. Esta no fue la única medida precautoria para salvar su responsabilidad frente al Gobierno y ante la opinión pública, pues el 14 de marzo acordó que en la publicación de las medidas que emanasen del Gobierno debería emplearse en lugar de la fórmula "conformándose con el parecer de la Junta" una nueva que dijera "no hallando reparo la Junta" ${ }^{10}$. La diferencia, aunque sutil, no deja de ser significativa y a pesar de

${ }^{4}$ En la Representación a S.M. de 18 de marzo manifestó claramente, por una parte, que los hechos ocurridos desde enero eran un obstáculo insuperable para que los Ministros siguiesen en sus funciones y, por otra, que la actitud de las provincias y el lenguaje de las Juntas y de quienes dirigían la opinión pública reflejaban una desconfianza que no desaparecería hasta que, entre otras cosas, fuese riombrado un gobierno "adicto". A.C., t. 41, 405$407 ;$ t. 35, 42 y 42v., sesión de mañana del 18 de marzo.

5 Exposición de la Junta de Galicia a la Junta Provisional de 15 de marzo. A.C., t. 41, 27-30v., 37-39v. y 41-43v.; t. 35, 66v. y $68 \mathrm{v}$., sesiones de mañana y tarde del 22 de marzo.

${ }^{6}$ El 13 y 14 de marzo, fecha de esta exposición, eran todavía Ministros titulares de estas Secretarías los del Antiguo Régimen: Duque de San Fernando, José María de Alós, Antonio González Salmón y Luis María de Salazar, respectivamente. A.C., t. 41, 300-304; t. 35, $23 v$. y 24 , sesión de mañana del 14 de marzo.

7 Exposición de los ciudadanos de las sociedades patrióticas de Lorencini y San Sebastián a la Junta Provisional A.C., t. 41, 248-256; t. 35, 149 y 149v., sesión de mañana del 14 de abril.

${ }_{8}$ Manifiesto de la Junta Provisional a las Cortes, en marqués de Miraflores, Documentos a los que se hace referencia en los apuntes histórico-criticos sobre la revolución de España. Londres, Of. Ricardo Taylor, 1834, t. I, 123.

${ }^{9}$ A.C., t. 41,401 ; t. $35,37 \mathrm{v}$., sesión de mañana del 17 de marzo.

10 Este acuerdo se trasmitió verbalmente al Gobierno por medio de una diputación de la 
que la primera respondía más a la realidad, la segunda, en cambio, le ponía a salvo incluso de sus propias iniciativas.

Además de las fricciones que la Junta protagonizó con el Rey, en las que el Gobierno siempre fue intermediario y partícipe en la medida en que no dimitió con el cambio de régimen, hubo otros enfrentamientos directos con el antiguo Ministerio. Tal fue el caso del nombramiento de Ministros para el Tribunal Supremo de Justicia al que procedió el Gobierno sin consultar previamente con la Junta, a propósito del cual tomó el acuerdo mencionado antes ${ }^{11}$. Otro caso de enfrentamiento lo protagonizó el Ministro de Hacienda, González Salmón, con motivo del destino que debía darse a los bienes del suprimido Tribunal de la Inquisición, al deslizar en un oficio a la Junta si debía cumplirse el decreto de las Cortes de Cádiz de 13 de septiembre de 1813, por el que los bienes de la Inquisición debían emplearse en el pago de los intereses de la deuda nacional, ya que nunca llegó a ponerse en vigor. La Junta le contestó destempladamente que el citado decreto no se llevó a efecto por el regreso del Rey y el restablecimiento del Tribunal, no por culpa del Crédito Público, con grave perjuicio para la Nación ${ }^{12}$.

También fue patente la tibieza y el escaso o nulo interés en sacar adelante las reformar que debían conducir a la consolidación del nuevo sistema. El antiguo Ministerio, que colaboró eficazmente con Fernando VII para dilatar en lo posible la institucionalización liberal, siempre fue a remolque de la Junta quien ejerció realmente la tracción, y por tanto, el poder. La propuesta del Ministro de Estado, Duque de San Fernando y de Quiroga, para que la Junta dijese si "cree conducente el restablecimiento de los Ministerios de la Gobernación de la Península y de Ultramar" no tuvo la fuerza de una franca iniciativa porque en ese caso hubiera propuesto dicha separación, por lo demás acorde con la Constitución, sin ninguna timi$\operatorname{dez}{ }^{13}$.

Junta, pero quedó por escrito, como otros acuerdos por ella tomados, y reflejado en las Actas. A.C., t. 41,$403 ;$ t. $35,23 \mathrm{v}$. y 24 , sesión de mañana del 14 de marzo.

${ }^{11}$ El decreto del 14 de marzo omitió entre los Ministros del Supremo Tribunal de Justicia a algunos que ya lo fueron en 1814 y nombró otros que no merecían confianza, a pesar de la advertencia de la Junta el dia anterior. Este hecho obligó a una rectificación posterior. Por si ya fuera poco el disgusto de la Junta, varios ciudadanos de Madrid en una exposición del 14 de marzo rubricada con treinta y nueve firmas, le acusaban de equivocaciones y falta de energía, entre otras cosas, por estos nombramiento del Tribunal Supremo de Justicia "que han tratado de comprometer a S.M.". A.C., t. 41, 300-304; t. 35, 23v. y 24, sesión de mañana del 14 de marzo.

12 Oficio del Ministro de Hacienda a la Junta del 13 de marzo, A.C., t. 39, 124-125 y Contestación al Ministro del 17 de marzo, A.C., t. 39, 126-128v.; t. 35, 37 y 42, sesiones de mañana del 17 y 18 de marzo.

${ }_{13}$ Oficio del Ministro de Estado al Vicepresidente de la Junta Provisional de 10 de marzo, A.C., t. 40,10 y $10 \mathrm{v}$; t t. 35,7 , sesión de tarde del 10 de marzo. 
En el mismo sentido llama la atención el envío a la Junta por el Ministro de la Gobernación, José García de la Torre, el 14 de marzo ${ }^{14}$, del expediente y la circular elaborados por el Consejo de Castilla en cumplimiento del Real decreto de 6 de marzo para la celebración de Cortes ${ }^{15}$ cuando cuatro dias antes él mismo como Ministro de Gracia y Justicia le había pedido que "sin demora acuerde lo conveniente para su pronta convocatoria" ${ }^{16}$. Naturalmente la Junta le devolvió los documentos diciendo que ya había adoptado sus propios acuerdos ${ }^{17}$ muy alejados, claro está, de una convocatoria a Cortes tradicionales. Este envío estaba, ni siquiera como antecedente, fuera de lugar a no ser que a esas alturas el Gobierno de Fernando VII pretendiera solapadamente el mantenimiento del Antiguo Régimen.

Justo al dia siguiente, 18 de marzo, de pedir al Rey que el nuevo Ministerio lo formaran personas capaces y "reconocidas por amigos del sistema constitucional", es decir, cuando los días del Gabinete estaban contados y su destitución cantada, la Junta llamó enérgicamente la atención del Ministro de la Gobernación en dos aspectos fundamentales: publicar todas las noticias referentes a la reposición de las instituciones constitucionales y acelerar los trabajos conducentes a ese fin ${ }^{18}$. De esta manera dejó patente, una vez más, su creencia en la falta de voluntad del Ministerio para llevar a término el cambio emprendido y la justificación de su propia existencia sin la cual el cambio no se hubiera hecho al menos pacíficamente.

En cuanto a las relaciones de la Junta Provisional con el Gobierno impropiamente llamado constitucional ${ }^{19}$, parace lógico pensar que, si no desde el primer momento, sí poco a poco, conforme los Ministros iban tomando las riendas de los asuntos de sus propias Secretarías, la Junta se hubiera ido retrayendo de participar, cuanto más de mandar, en la ma-

${ }^{14}$ A.C., t. 40, 499; t. 35, 27, sesión de mañana del 15 de marzo.

${ }^{15} \mathrm{El}$ documento se refiere al decreto del 8 de marzo, pero forzosamente tiene que tratarse del decreto del día 6 , único que ordenaba al Consejo de Castilla tomar las medidas necesarias para la celebración de Cortes. Gaceta E., 7 marzo 1820, n. 30, 237.

${ }^{16}$ Oficio del Ministro de Gracia y Justicia a la Junta Provisional del 10 de marzo, A.C., t. $40,480-481$.

17 A.C., t. 40, 500; t. 35, 27, sesión de mañana del 15 de marzo.

${ }^{18}$ En su oficio la Junta manifestaba que no habia hecho públicos sus trabajos para que fuese el Gobierno quien trasmitiese las noticias necesarias para tranquilizar la opinión y que cualquier dilación en los trabajos sólo conseguiría el descrédito de la Junta y del Gobierno. A.C., t. 40,21 ; t. $35,39 \mathrm{v}$., sesión de tarde del 17 de marzo.

${ }_{19}$ Constitucionalmente correspondia al Rey nombrar "libremente" los miembros de su Gabinete (Tít. 7, cap. I, art. 171). Excepto el Marqués de las Amarillas, ningún nombramiento reunió ese requisito. Por tanto, el empleo del término "primer gobierno constitucional" se hace en el sentido de Gobierno nombrado estando vigente la Constitución de 1812. 
yor parte de ellos. Sin embargo, no fue así; aquélla siguió las mismas pautas que con el anterior, sin cederle ninguna de sus facultades adquiridas, bien por el decreto de creación, bien por el uso o la costumbre, y las relaciones no estuvieron exentas de discordancias y hasta de enfrentamientos.

La caracteristica más sobresaliente de esta relación fue la moderación de la Junta frente a actitudes más drásticas de algunos Ministros en el terreno no tanto ideológico como práctico. Hay que hacer, sin embargo, la salvedad de que no siempre prevaleció esa moderación de la Junta, pero contribuyó positivamente a una transición sin convulsiones. El primer episodio por esta razón se produjo con el Ministro interino de la Gobernación de la Península y titular de Ultramar, Antonio Porcel. La causa fue el decreto de 26 de abril que confinaba en Alava, Vizcaya, Guipúzcoa y Castilla hasta Burgos "a los españoles que estén o hayan estado refugiados en Francia" por haber seguido al Gobierno de José Bonaparte, poniendo esta restricción al decreto del 23 del mismo mes, que permitía la entrada de estos refugiados en territorio español sin limitación alguna para acomodarse a lo que las Cortes de Cádiz dictaron sobre el particular ${ }^{20}$. La Junta hizo patente al Ministro en una larga y enérgica exposición su total desacuerdo con esta medida en abierta oposición a la Constitución y a los decretos de las Cortes porque vulneraba la libertad civil de todos los españoles mientras no hubiera sentencia judicial y porque aquéllas nunca dispusieron ni el extrañamiento ni el confinamiento de quienes sirvieron al "gobierno intruso" 21. En consecuencia, pidió que se revocase el decreto del 26 y se publicase una aclaración del de 23 en el sentido de que los refugiados y sus familiares, mientras no mediase sentencia, podian asentarse libremente en el territorio nacional aunque hubieran perdido la ciudadanía como decretaron las Cortes ${ }^{22}$. Esta aclaración nunca tuvo lugar,

20 Real decreto de 23 de abril en Gaceta, 27 abril 1820, n. 72, 479. Real decreto de 26 de abril en Gaceta, 29 abril 1820, n. 73, 488 y 489. El decreto de 23 de abril fue el resultado de una consulta del Ministro a la Junta sobre el regreso solicitado por emigrados a Francia. En ese momento la Junta ya advirtió que los decretos de las Cortes sólo eran aplicables a los empleados que sirvieron al Gobierno francés y que permanecieron en las zonas que iban quedando libres, pero no a los que emigraron con el Ejército francés. Por tanto, debía permitírseles el regreso. A.C., t. 40, 214-217; A.C., t. 35, 172 y 172v., sesión de mañana del 21 de abril.

${ }^{21}$ Además de las razones legales aducia una de tipo humanitario y otra política: confinándolos en determinadas provincias, lo único que se conseguia era mortificarlos más y reunir en ellas una "multitud de descontentos". Exposición de la Junta Provisional al Ministro de la Gobernación de la Península, de 1 de mayo, A.C., t. 40, 280-283; A.C., t. 35,210 bis y 210 bis v., sesión de mañana de 1 de mayo.

${ }^{22}$ Las Cortes de Cádiz dispusieron en tres Reales decretos las medidas a tomar respecto a los empleados que sirvieron al Gobierno francés: En los artículos III y IV del Decreto CLXXXIV sobre varias medidas para el gobierno de las provincias que vayan quedando libres, 
prevaleciendo, por tanto, la decisión del Ministro que se salía de los límites legales.

El 9 de mayo el Ministro de Gracia y Justicia, Manuel García Herreros, planteó a la Junta el delicado tema de los diputados que firmaron el Manifiesto del 12 de abril de $1814{ }^{23}$ para proceder contra ellos en el sentido señalado por el artículo 172 de la Constitución que restringía la autoridad del Rey para impedir suspender, disolver o embarazar las Cortes y declaraba traidores a quienes "le aconsejasen o auxiliasen en cualquier tentativa" ${ }^{24}$. No es que la Junta hasta ese momento no se hubiera planteado el problema, incluso recibió presiones para que lo tomase en consideración y actuase ${ }^{25}$, pero nunca se había decidido por una solución, ni siquiera transitoria, porque siendo los autores diputados cuando firmaron el documento, sólo correspondía a las Cortes nombrar un tribunal para juzgarlos y prefirió esperar hasta que éstas se reuniesen en la creencia de que esta dilación no causaría perjuicio. Ahora bien, ante el requerimiento del Ministro, siguió afirmando que prefería que fueran las Cortes quienes tomasen

1 de agosto de 1812, en Decretos de las Cortes, t. III,. 52-54, mandaba cesar en el ejercicio de sus funciones a todos los empleados que habiendo sido nombrados o no por el Gobierno intruso, to hubieran servido. El artículo I del Decreto CXCII sobre las medidas para asegurar la confianza de la Nación respecto de los empleados y otras personas públicas, 21 de septiembre de 1812, en Decretos de las Cortes, t. III, 84-87, establecía que los empleados cesados por haber servido al Gobierno intruso citados en el decreto de 11 de agosto de 1812, "no podrán ser propuestos ni obtener empleo de ninguna clase o denominación que sea, ni ser. nombrados ni elegidos para oficios de Concejo, Diputaciones de provincias, ni para Diputados de Cortes, ni tener voto en las elecciones" mientras que el artículo II consideraba que el anterior "no estorbará de modo alguno la formación de la causa a que por su conducta se hayan hecho acreedores los empleados y demás personas comprendidas en el artículo anterior". El artículo I del Decreto CCIX en el que se prescriben las reglas para la rehabilitación de los empleados que continuaron en sus destinos bajo el gobierno del Rey intruso, 14 de noviembre de 1812, en Decretos de las Cortes, t. III, 166-168 rehabilitó a los empleados públicos nombrados por la autoridad legítima que, aunque se hubieran mantenido en sus puestos bajo el Gobierno intruso, y no teniendo causa criminal pendiente, serian repuestos en sus empleos anteriores, pero por el artículo VII se establecía que no serían rehabilitados ni repuestos "los empleados públicos nombrados por la autoridad legítima que, en el caso de haber salido de sus oficinas a pais libre, han permanecido en el ocupado por el enemigo, aunque sin servir al gobierno intruso, no tendrán derecho a la reposición en sus anteriores destinos".

${ }^{23}$ Representación y Manifiesto que algunos Diputados a las Cortes ordinarias firmaron..., 12 de abril de 1814. Imprenta de Collado. A.C., t. 36, 366-397. Sobre este tema véase María Cristina Diz-Lols. El manifiesto de 1814. Pamplona, Universidad de Navarra, 1967, 285 págs.

${ }_{24}$ Oficio del Ministerio de Gracia y Justicia a la Junta pidiendo informe para proceder con los Diputados que firmaron la Representación y Manifiesto de 12 de abril de 1814 porque, a decir del Ministro, "la tranquilidad pública se halla comprometida". A.C., t. 36, 361 y $361 \mathrm{v}$.; t. 35,235 y $235 \mathrm{v}$., sesión de tarde del 9 de mayo.

${ }^{25}$ Según la propia Junta hubo quejas al respecto desde el momento mismo en que el Rey juró la Constitución, como consta en su discusión del tema los dias 9 y 10 de mayo. 
las medidas señaladas en el artículo 172, pero propuso la solución intermedia de ponerlos bajo custodia en caso de peligrar el orden público, dato éste que afirmó desconocer, y que el Ministerio debía sopesar. La Junta fue tan consciente de la moderación de su propuesta en comparación a lo solicitado que lo hizo constar expresamente, junto con las anteriores consideraciones, en respuesta al Ministro ${ }^{26}$. El Real decreto consiguiente se atuvo a estas indicaciones, con la excepción en la reclusión en monasterios o conventos de los diputados obispos ${ }^{27}$ por decisión del Rey y para tranquilidad de los miembros eclesiásticos de la Junta, el cardenal Borbón, su presidente, y el Obispo de Michoacán.

Actitud semejante a las dos anteriores mostró la Junta respecto a las restricciones que el Ministro de Estado, Evaristo Pérez de Castro, quiso poner el 5 de junio a la entrada de extranjeros en España para evitar la perturbación del orden público ${ }^{28}$. La Junta se mostró contraria a adoptar medidas excepcionales de tipo general contra todos los extranjeros porque "el pueblo español es poco influenciable por las sugestiones" y porque la propuesta rozaba la seguridad individual. En todo caso, el tema, estando tan cerca la reunión de las Cortes, le pareció lo suficientemente trascendente como para dejarlo a su decisión ${ }^{29}$. Ante la insistencia del Ministro, el 13 de junio volvió a ratificarse en las mismas razones y añadió las ventajas económicas y políticas de la inmigración extranjera por lo que suponia de aporte de capitales y propaganda exterior del nuevo régimen español ${ }^{30}$. En este caso al constante dilema orden-libertad, se añadía la repercusión exterior de una medida restrictiva que podía deslucir la imagen que se pretendía dar. La Junta no veía tantos fantasmas como los Ministros, ni creía que había necesidad de tomar medidas drásticas o excepcionales ni en los casos citados ni en ningún otro. Para ella bastaba con la aplicación de la legislación, pero sin estridencias. Es posible que al

${ }^{26}$ Si peligra el orden público “... el Ministerio no dude en ponerlos bajo custodia con las consideraciones propias de su rango de diputados y para que se vea la moderación que con los delincuentes tiene un Gobierno libre". El acuerdo fue adoptado unánimemente por la Junta sobre el informe elaborado por su vocal Mateo Valdemoros y expuesto verbalmente a todos los Ministros dado lo delicado del tema. A.C., t. 35, 236-238v., sesión de mañana del 10 de mayo; t. 36,360 y $362-365 v$.

27 Real decreto de 15 de mayo en Gaceta, 16 de mayo 1820, n.80, 553.

${ }^{28}$ Oficio del 5 de junio del Ministro de Estado a la Junta Provisional para que informe sobre un reglamento relativo a la entrada de los extranjeros en el Reino, A.C., t. 36, 116-117 v.; t. 35, 314, sesión de tarde del 5 de junio.

${ }_{29}$ Mientras tanto el Gobierno podía tomar precauciones con aquellos extranjeros "con principios que puedan ser perniciosos". A.C., t. 36, 118 y 118v.; A.C., t. 35, 314, sesión de tarde del 5 de junio.

${ }^{30}$ A las razones de orden público, añadía el Ministro que también en otros países se habian adoptado medidas semejantes. A.C., t. 36, 121-125v. La Junta creyó que bastaba con vigilar a los extranjeros que fueran sospechosos pero sin vulnerar su seguridad personal. A.C., t. 36, 119-125v.; A.C., t. 35, 353v.-354v., sesión de mañana del 14 de junio. 
no haber sufrido sus miembros consecuencias desagradables al regreso del Rey en el 14 y no mantener relaciones directas con él, carecieran también del temor exacerbado a un retroceso que experimentaban los "presidiarios"; temor que les llevaba a actitudes mucho menos tolerantes y ponderadas que las de la Junta Provisional.

Una segunda característica de las relaciones de la Junta con el Gobierno constitucional fue el buen entendimiento entre ambos cuando los intereses fueron acordes y el apoyo expreso de la Junta en aquellos temas que lo requerían porque el apoyo tácito se sobreentendía en el resto de los asuntos. Respecto a la concesión de grados militares, el Ministro de la Guerra, Marqués de las Amarillas, comunicó a la Provisional el 3 de abril, que iba a circular la ratificación de la orden dada por las Cortes sobre la prohibición absoluta de conceder grados Militares como norma general ${ }^{31}$. La Junta le agradeció esta iniciativa y contestó a las dos aclaraciones que pedía el Ministro en el sentido más satisfactorio para éste ${ }^{32}$. Igual satisfacción por su "celo" mostró la Junta al mismo Ministro cuando, anticipándose a sus deseos, le propuso el 10 de abril la ratificación del decreto de las Cortes sobre la asistencia a los militares inválidos en acción de guerra ${ }^{33}$. La Junta "aplaudió" las medidas propuestas por el Ministro de Hacienda, José Canga Argüelles, para cubrir las vacantes de su ramo, con la debida publicidad en la convocatoria de plazas y en su resultado, para no comprometer al Gobierno y asegurar la justicia y el acierto de la elección ${ }^{34}$. En los citados ejemplos, como en otros muchos, se pone de manifiesto la alegría de la Junta ante la iniciativa de los Ministros. Estaba acostumbrada desde la etapa que gobernó con el gabinete del Antiguo Régimen a ser ella la propulsora de cualquier medida por insignificante o secundaria que pudiera parecer.

31 Petición de consulta del 3 de abril del Ministro de la Guerra a la Junta sobre la prohibición de conceder grados militares hasta la organización del ejército. A.C., t. 38, 77 y $77 \mathrm{v}$;; t. 35,107 , sesión de mañana del 4 de abril. Circular de 16 de abril del Ministerio de la Guerra con la ratificación de la orden de 27 de agosto de 1811 en Gaceta, 20 abril 1820, n. 68, 447. Orden en que se prohibe por punto general la concesión de grados militares, 27 de agosto de 1811, en Decretos de las Cortes, t. I, 206 y 207.

${ }^{32} \mathrm{La}$ orden debía ser interina hasta que las Cortes decidieran la definitiva organización del Ejército. En el caso de Ultramar, debian confirmarse los grados concedidos porque aquellas autoridades tenian poder para hacerlo mientras no se les derogasen dichas facultades. A.C., t. 38,78 y 78 v.; t. 35,143 y 143., sesión de tarde del 13 de abril.

${ }_{33}$ A.C., t. $38,128-134$; t. $35,137,137 \mathrm{v}$. y 171 , sesiones de tarde del 11 de abril y de mañana del 21 de abril. Circular del 12 de abril del Ministerio de la Guerra y decreto del 13 de marzo de 1814 en Gaceta, 20 abril 1820, n. 68, 443-447.

${ }_{34}$ A.C., t. 39, 304-314; t. 35, 151 y $151 v$., sesión de mañana del 15 de abril. Real decreto del 22 de abril de 1820 en Gaceta, 4 mayo 1820, n. 75, 505 y 506. 
A cambio, también el Gobierno recibió el apoyo de la Junta en situaciones más o menos comprometidas. El Ministro de la Guerra le manifestó su satisfacción por la respuesta que dio a la Junta de Galicia con motivo de las "observaciones" de ésta acerca del licenciamiento de tropas ${ }^{35}$. Las pretensiones de la de Galicia iban dirigidas a dejar sin efecto la Real orden so pretexto de la necesidad de tropas frente a un hipotético peligro exterior y del derecho de éstas a celebrar la reunión de Cortes ${ }^{36}$. La contestación de la Provisional el 22 de abril fue categóricamente favorable al licenciamiento adoptado por el Gobierno ${ }^{37}$. De ahí la satisfacción del Ministro, que vio cómo en otras ocasiones en que la Junta recibió presiones su autoridad quedó mermada, por el incuestionable apoyo recibido ${ }^{38}$.

La buena coordinación entre el Gobierno y la Junta quedó patente en las reacciones del poder central frente a los sucesos ocurridos en la Capitanía General de Castilla la Vieja durante el mes de abril. En términos generales, se redujo a la destitución del Conde de Montijo como Capitán General de la zona y a su sustitución por el General Santocildes cuya autoridad se negó a reconocer, en ausencia del Conde de Montijo, el Teniente General Juan Martín Díez "El Empecinado", con el apoyo de parte del Regimiento Imperial Alejandro de guarnición en Valladolid ${ }^{39}$. El dictamen de la Junta en esta ocasión, muy en la línea del Marqués de las Amarillas cuando se trataba de casos de indisciplina, fue tajante y no guardó contemplaciones con ninguno de los implicados en el incidente ${ }^{40}$. Por otra parte, el retraso

35 Real orden circulada por el Ministerio de la Guerra para el licenciamiento en todos los cuerpos del ejército de los cumplidos hasta el final de 1817, 2 de abril de 1820, en Gaceta, 6 abril 1820, n. 62, 399.

${ }^{36}$ La Junta de Galicia decía que era necesario acallar los derechos individuales cuando las necesidades de la Patria lo requerian; que las potencias extranjeras, a la vista del afianzamiento del sistema en España, podian iniciar una política de atracción hacia los descontentos y que las tropas tenían derecho a coronar, con la reunión de Cortes, una empresa iniciada por ellas. Oficio de la Junta de Galicia a la Junta Provisional, La Coruña, 15 de abril de 1820. A.C. t. $37,272-273$.

${ }^{37}$ La Junta Provisional le decia a la de Galicia que para aprobar el licenciamiento de los cumplidos hasta 1817 tuvo a la vista los suficientes datos para saber que la medida ofrecia más ventajas que inconvenientes. Que aquellas personas a quienes afectase la medida que quisieran quedarse al servicio del ejército podían hacerlo y "tendrian un nuevo derecho a la gratitud de la Patria". Finalmente, que el Gobierno y la Junta se encargaban de que las potencias extranjeras no se ingiriesen en asuntos internos. A.C., t. 35, 173, sesión de mañana del 21 de abril; t. 37, 270-271v.

${ }_{38}$ Contestación del Ministro de la Guerra a la Junta el 25 de abril, A.C., t. 37, 274; t. 35, 194, sesión de tarde del 26 de abril.

39 Véase el expediente n. 29 del mes de marzo del Ministerio de la Guerra Sobre los sucesos ocurridos en Castilla la Vieja con el Conde de Montijo. A.C., t. 37, 317-490 bis.

40 Al Conde de Montijo debía enviársele de cuartel a Murcia, "El Empecinado" debía presentarse en Madrid, los coroneles Alejandro O'Donell, del Imperial Alejandro, y Sierra podian ser destinados a La Mancha o Extremadura y el Regimiento citado debía salir de 
de dos días en la salida de Madrid hacia sus destinos de los oficiales trasladados no se debió a negligencia sino al rumor de sublevación y a la precaución del Ministro de mantenerlos para que no pensasen que se les temía. La Junta vio con satisfacción que el Gobierno "tiene medios para reprimir cualquier sedición y energía para hacerlo" ${ }^{41}$.

A pesar de lo dicho anteriormente, no puede afirmarse de ninguna manera que todo fuera un camino de rosas entre el Ministerio constitucional y la Junta Provisional. No faltaron los problemas, tanto por el choque de facultades de ambos poderes como por la desavenencia con algunos ministros en temas concretos.

La primera reclamación formal de sus facultades por parte de la Junta en esta etapa se produjo con motivo de la orden recibida por el General en Jefe del Ejército de Andalucía, Juan O'Donojú, para embarcar tropas en Cádiz con destino a América sin su conocimiento oficial ${ }^{42}$. En consecuencia, el 13 de abril elevó formalmente al Rey su protesta, en términos bastante duros, exigiendo su derecho a conocer cualquier medida que tomase el Gobierno "mientras S.M. no se sirva variar o revocar las atribuciones que le señala el decreto de 9 de marzo" ${ }^{43}$. La reconvención iba dirigida, naturalmente, al Ministro de la Guerra quien le contestó el mismo día que en modo alguno pensaba llevar a término la decisión sin consultar previamente con la Junta y el Consejo de Estado ${ }^{44}$. De cualquier forma, aún tratándose eufemísticamente de una ignorancia en ciernes de sus facultades, la Junta no dudó un instante en reclamarlas.

Valladolid con un jefe de confianza a donde éste creyese oportuno. A.C., t. 35, 224v.-225v., sesión de mañana del 6 de mayo; Oficio de la Junta del 6 de mayo con su dictamen sobre los sucesos del 24 de abril en Valladolid, t. 37, 142-143.

41 Oficios de 15 y 16 de mayo del Ministro de la Guerra a la Junta y viceversa, A.C., t. 37 , $473-474$; t. 35, 258, sesión de mañana del 16 de mayo.

${ }_{42}$ El conocimiento de esta noticia, al decir de la Junta, lo obtuvo "por casualidad". Por esta razón decidió elevar al Rey una Exposición con oficio para el Ministro de la Guerra. A.C., t. 35,139 y $139 \mathrm{v}$., sesión de tarde del 12 de abril.

43 Justificó esta reclamación en que la opinión pública estaba convencida de su intervención en todas las medidas tomadas por el Gobierno, lo cual contribuía a la tranquilidad de aquélla, pero cargando sobre la Junta responsabilidades en asuntos que ella, como en este caso, no conocía y en que "no se ha excedido ni una sola vez en sus funciones". A.C., t. 35, 140-141, sesión de mañana de 13 de abril; Exposición de la Junta Provisional a S.M. sobre el envio de tropas a Costa Firorme, 13 de abril de 1820; A.C., t. 39, 15-16.

44 Toda la labor realizada hasta ese momento iba encaminada a "explorar voluntades", esto es, qué tropas estarian dispuestas a pasar a Ultramar, y reunir el material necesario para, en caso de ser aprobada esta disposición por el Rey, hacer el envío lo más rápidamente posible. Comunicación del Ministro de la Guerra a la Junta el 13 de abril. A.C., t. 39, 25-26v.; t. 35,150 , sesión de tarde del 14 de abril. 
A propósito de los emigrados españoles que huyeron a Francia con el Ejército francés, también se originó una situación semejante a la anterior, pero esta vez con el Ministro interino de la Gobernación de la Península, Antonio Porcel. El motivo fue la emisión de un segundo decreto, el 26 de abril, como ya se ha visto, restringiendo geográficamente el retorno de estos emigrados sin consultar a la Junta. A las razones de la Junta, ya analizadas, para desaprobarlo, hay que añadir su manifiesto desagrado por una medida tomada sin su acuerdo de manera que "sólo parece buscar en las consultas de la Junta la salvaguardia contra la opinión pública y la odiosidad de algunas medidas que necesariamente hay que tomar" ${ }^{45}$.

Consecuencia inevitable del ejercicio por parte de la Junta de su derecho a conocer y emitir dictamen sobre todos los temas de gobierno y de que se cumpliesen sus consejos, fue el enfrentamiento en algún momento con todos y cada uno de los Ministros a excepción del de Estado, Evaristo Pérez de Castro, que se incorporó cuando las relaciones exteriores no ofrecían problemas espinosos. Las respuestas a los requerimientos de la Junta fueron diferentes según los Ministros. Mientras que los de Guerra y Marina, Marqués de las Amarilla y Juan Jabat, respectivamente, hicieron valer sus razones frente a la diferente opinión de la Junta, el resto dio la callada por respuesta, tanto si seguían manteniendo su postura, como si rectificaban según el deseo de aquélla o si dejaban languidecer el tema.

La primera y la tercera fueron las actitudes que adoptó Antonio Porcel. Siendo Ministro interino de Gobernación de la Península, con ocasión del tema de los españoles emigrados a Francia, ni contestó a la petición de la Junta del 1 de mayo para que se rectificase el decreto de 26 de abril, ni cumplió su deseo. Como responsable interino de este mismo Ministerio, recibió el 9 de mayo una severa reprimenda de la Junta por atender las pretensiones de carácter personal de las Juntas Superiores de Cirugía y Farmacia y retrasar con ello la ejecución de los decretos de las Cortes ${ }^{46}$, solicitado por la Junta el 3 de abril para el restablecimiento del Tribunal Supremo de Salud Pública -Protomedicato- en un tema urgente por la proximidad del verano y la necesidad de medidas sanitarias para evitar los estragos de la peste ${ }^{47}$. Pues bien, a pesar del claro malestar de la Junta,

45 Vid. nota (20) de este artículo.

${ }^{46}$ Decreto LXXIX sobre el restablecimiento del Tribunal del Proto-medicato, 22 de julio de 1811, en Decretos de las Cortes, t. I, 180 y 181. Decreto XCll sobre las declaraciones y adiciones al decreto de 22 de julio último sobre el restablecimiento del Tribunal del Proto-medicato, 21 de septiembre de 1811, en Decretos de las Cortes, t. I, 233.

47 Documentación cruzada entre el Ministro y la Junta y representaciones de las Juntas de Cirugía y Farmacia. A.C., t. 40, 122-144; t. 35, 104, 211, 211v., 233v. y 234, sesiones de tarde del 3 de abril y 1 de mayo y de mañana del 9 de mayo. 
eludió el cumplimiento de su "mandato" y lo dejó, retrasándolo todavía más, para su sucesor Agustín Argüelles ${ }^{48}$. Como titular del Ministerio de la Gobernación de Ultramar, recibió el 18 de junio un oficio de la Junta pidiéndole información sobre el nombramiento de comisionados que debían ir a América con el encargo extraordinario de preparar la pacificación de aquellos territorios ${ }^{49}$. Si alguna vez existió tal proyecto, nunca más se supo de él porque el Ministro no contestó y no tenemos noticias de que se llevase a cabo antes de la celebración de las Cortes. Este modo de afrontar las dificultades frente a los criterios de la Junta sin llegar nunca al choque respondía perfectamente al juicio del Ministro de la Guerra acerca de su inteligencia y sentido práctico ${ }^{50}$.

El 4 de mayo recibió la Junta, en respuesta a una solicitud que hizo el anterior Ministro de Hacienda, Antonio González Salmón, el estado de ingresos y gastos de la Tesorería General y otros datos económicos para poder opinar sobre la posibilidad de remediar la escasez de fondos ${ }^{51}$. Después de esperar un mes, los datos que le envió José Canga Argüelles le llenaron de irritación porque "si se toma la molestia de repasar los documentos remitidos por la Junta al Ministro y viceversa, ... podrá advertir que el pedido de la Junta está lejos de haber sido satisfecho". Así pues, además de echarle en cara su falta de interés y seriedad en el tema más urgente de su Departamento al limitarse a trasladar un informe de la Tesorería General, y de señalarle todos los defectos de que adolecía su información, le devolvía el expediente porque en esas condiciones no podía emitir un dictamen serio ${ }^{52}$. No hubo respuesta concreta del Ministro a esta reconvención, aunque se tomaron paulatinamente medidas para solucionar la falta de numerario de la Hacienda.

48 Real Decreto de (s.d.) mayo de 1820 restableciendo el Tribunal del Protomedicato en Gaceta, 10 junio 1820 , n. 92, 668 y 669 .

49 La Junta consideraba este tema, igual que el envio de tropas, de la mayor importancia y gravedad. Quizás precisamente por conocer la opinión de negativa tajante al último tema, así como la idea de la Junta de que el fin de las hostilidades en Ultramar sería automático con el nuevo sistema y su repugnancia a utilizar medios extraordinarios, renunció a este método de pacificación. A.C., t. 42, 57 y 57v.; t. 35, 366, sesión de mañana del 18 de junio.

50 "Porcel era el que tenía más talento y más mundo". AmARILLAS, op. cit., t. II, 91.

51 Oficio del 7 de abril del Ministro de Hacienda a la Junta pidiéndole urgentemente su propuesta para remediar la falta de fondos de la Tesorería General. A.C., t. 39, 256-260. El 9 de abril la Junta contestó que para dar su opinión necesitaba una serie de datos sobre el estado pormenorizado de ingresos y gastos de la Tesorería General divididos en urgentes y menos urgentes, medidas tomadas para obligar a las provincias a cumplir sus obligaciones con la Hacienda, observación de la ley del máximo y de la prohibición de disfrutar dos sueldos. A.C., t. 39, 261-263v.; t. 35, 127v. y 128, sesión de tarde del 9 de abril.

52 Contestación del 11 de mayo acordada por todos los Miembros de la Junta al Ministro de Hacienda, Canga Argüelles, A.C., t. 39, 252-253; t. 35, 242 y 242v., sesión de mañana del 11 de mayo. 
También el Ministro de Gracia y Justicia, Manuel García Herreros, recibió la advertencia de la Junta a propósito de la forma inadecuada, según ella, de proveer prebendas eclesiásticas y plazas para el Tribunal Supremo $\mathrm{y}$, además, sin consultarle. El tema, suscitado por Ballesteros, se discutió ampliamente en su seno en las dos sesiones del 28 de mayo, teniendo en cuenta su dictamen de restablecimiento del Tribunal Supremo y las del Consejo de Estado, órgano asesor del Ministro en este caso, al que correspon día la propuesta para la provisión de estos empleos ${ }^{53}$. El 5 de junio se aprobó la exposición que desautorizaba la política del Ministro en el sentido de que los nuevos cargos para el Tribunal debían ser interinos, como los repuestos del antiguo, para poder examinar su actuación en los últimos seis años y que se podía premiar a los eclesiásticos sin acudir a la provisión de prebendas ${ }^{54}$. La contestación de García Herreros fue una nota publicada en la Gaceta con el nombramiento de los nuevos Ministros del Tribunal Supremo sin especificar su calidad de propietarios o interinos ${ }^{55}$. Con esta sutileza eludía la moción de la Junta.

Ni siquiera el "divino Argüelles", se libró como Ministro de la Gobernación de la Península de recibir una reprimenda de la Junta en términos, por otra parte, bastante insolentes aunque no carentes de razón, puesto que fueron temas sobre los que constantemente insistió a partir de la convocatoria de Cortes. Así, el 29 de mayo le "llamaba por última vez la atención" para que tomase las medidas necesarias a fin de que el 26 de junio estuviesen dispuestas todas las oficinas y la redacción del Diario de las Cortes ${ }^{56}$. Por toda respuesta, el 25 de junio le comunicó el Ministro que el Jefe Político de Madrid le había entregado las llaves de las puertas principales del salón de Cortes ${ }^{57}$.

53 Se encargó al mismo Vicepresidente poner por escrito las reflexiones de la Junta para tomar de acuerdo con ellas la decisión final. A.C. t. 35, 293-294, sesiones de mañana y tarde del 28 de mayo.

54 Acuerdo de la Junta Provisional del 5 de junio, A.C., t. 36, 415-416v.; t. 35, 315v.-320v. sesión de tarde del 5 de junio.

55 Se nombró como Presidente al Consejero honorario de Estado, Antonio Cano Manuel y como Ministros a Francisco Nogués, Benito Hermosilla, Francisco Javier Caro, Francisco Alfonso de Tuero, José Calatrava, Pedro Silves, Antonio Villaurrutia, Ramón Giraldo y Miguel Antonio Zumalacárregui. Gaceta, 22 junio 1820, n.97, 718 y 719 . A Francisco Marchamalo se le incluyó, debido a una equivocación en la nota anterior, en la Gaceta, 27 junio 1820, n. ${ }^{\circ} 99$, 739. En total, los diez magistrados por cuyo nombramiento habia llamado la atención el General Ballesteros.

${ }^{56}$ Las oficinas de las Cortes debian estar físicamente dispuestas y atendidas por el personal completo previsto en su reglamento interno en calidad de interino hasta la llegada de los propietarios o el nombramiento de las Cortes para las vacantes. Del mismo modo, debía estar organizada la redacción del Diario y de las Actas de las sesiones y la Imprenta Nacional para evitar retrasos en su publicación. A.C., t. 40, 651-652 y t. 35, 295v. y 296, sesión de mañana del 29 de mayo.

57 A.C., t. 40,646 y 646 v. y t. 35, 396, sesión de mañana del 26 de junio. 
Estos cuatro Ministros eludieron o acataron los deseos de la Junta como mejor pudieron, pero nunca llegaron al enfrentamiento y mucho menos al choque frontal. Prescindieron o intentaron prescindir de ella en lo posible, que fue poco realmente, y en lo imposible cedieron silenciosamente. En cambio, son notables por todo lo contrario las actitudes de los dos miembros militares del Gabinete, titulares de las carteras de Marina y Guerra, mucho más francas que las del resto y, en consecuencia, menos diplomáticas.

Juan Jabat tuvo dos enfrentamiento con la Junta. El primero de ellos en abril como Ministro interino de Estado y el segundo en junio como titular de Marina. No es, pues, la cantidad lo que hace significativa su relación con la Junta, sobre todo si se tiene en cuenta que fue el primero que formó parte del Gobierno desde el 18 de marzo, sino la calidad de estos "encuentros". En abril tuvo la Junta noticias extraoficiales del viaje que iba a hacer a Madrid para ver a Fernando VII el enviado del Gobierno francés Marqués de Latour du Pin y manifestó una fuerte oposición a él sobre todo por la calidad del personaje. Pues bien, en la contestación que dio Jabat a la Junta sobre la mala impresión y el disgusto que le había producido al Rey su sospecha de insinceridad, se puso abiertamente del lado del Monarca. Se quejó de la actitud de la Junta, alabó con elocuencia la buena voluntad de Fernando VII en la aceptación del sistema constitucional y aconsejó que se dejase realizar el viaje del Marqués ${ }^{58}$. De nada le sirvió porque la Junta volvió a insistir para que se "evite la venida de cualquier enviado que parezca sospechoso" 59 . Al margen del incidente, destaca el tajante desacuerdo con la Junta y la encendida y, al parecer, sincera alabanza del Rey ante tamaño desaire. Es el único caso encontrado en la documentación en que un Ministro se opuso a la decisión de la Junta con una defensa tan encendida de la dignidad real, aunque prevaleció la suspicacia de la Junta sobre la diplomacia de Jabat.

La disparidad de criterios respecto a las atribuciones de la Marina entre el Ministro y la Junta, dio lugar al segundo desacuerdo entre ambos. En esta ocasión se enfrentaban la concepción militar del Ministro y la política de la Junta. La pretensión de Juan Jabat iba encaminada a controlar desde su Departamento, como le correspondía, la Marina nacional. Para ello, el 2 de junio le daba la noticia de las irregularidades que Quiroga estaba cometiendo en el Departamento de Cádiz negándose a entregar el navío

${ }^{58}$ Oficio del 3 de abril del Ministro interino de Estado, Juan Jabat, a la Junta. A.C., t. 36 , $33-40$ y t. 35, 102v.-103v., sesión de mañana del 3 de abril.

59 Contestación del 3 de abril de la Junta al Ministro de Estado, A. C.,., t. 36, 28-29v. y t.35, 104v. y 105, sesión de tarde del 3 de abril. 
San Julián y el Arsenal de la Carraca ${ }^{60}$. A partir de ese momento la Junta comenzó a dar largas al problema para evitarse dificultades con uno de los jefes del Ejército de la Isla y, por eso, las contestaciones a los requerimientos del Ministro fueron de lo más peregrinas ${ }^{61}$. Respecto al navio dijo que no habría problemas si a Quiroga se le hacia saber por el conducto reglamentario que la orden procedía del Rey, lo cual exasperó bastante al Ministro porque estaba claro que ésas eran las órdenes que le había trasmitido el Capitán General del Departamento de Cádiz, el conducto de ordenanza, y que el tema se hallaba dentro de las atribuciones de su Ministerio ${ }^{62}$. El contencioso entre Ejército y Marina sobre la devolución del Arsenal de la Carraca se fue dilatando hasta el 5 de julio, fecha en que la Junta decidió favorablemente porque al día siguiente se reunía el Congreso, descargando en las Cortes su responsabilidad. El problema no fue el desacuerdo entre los Ministros de Guerra y Marina ${ }^{63}$, tan contrarios a la desobediencia o indisciplina, sino el temor de la Junta a contrariar en exceso a los autores del pronunciamiento del 1 de enero ${ }^{64}$. Prevalecieron de este modo los intereses políticos de la Junta por encima de la autoridad de sus dos Ministros. En los dos casos analizados los resultados para Juan Jabat fueron negativos y estuvieron acompañados por el público menoscabo de sus funciones, contribuyendo a ello sin duda el delicado carácter de los temas.

60 El Ministro razonó que no era necesario conservar la línea, a la que pertenecía el navio San julián, guarnecida por Quiroga con la división a su cargo. Dicho navío, junto con otro, debía zarpar para El Callao y, además, en el lugar en que estaba situado y con pólvora en su interior constituía un grave peligro. Por otra parte, la ocupación del Arsenal por fuerzas que no eran de Marina, impedía a los jefes ejercer sus facultades y continuaba el despojo de material. A. C., t.38, 463-466.

61 Con la contestación de circunstancias del 4 de junio la Junta se abstenía de decir nada más y no hacía mención para nada del Arsenal. A. C., t. 38, 467 y t. 35, 304, sesión de tarde del 2 de junio.

${ }_{62}$ Quiroga no tenía razón ninguna para retrasar la entrega del navío del 13 al 28 de mayo, puesto que luego lo hizo sin nueva orden como le había comunicado el Capitán General y se lo transmitía a la Junta en oficio del 5 de junio, volviendo a reclamar el Arsenal. A. C., t. 38 , 468-469.

${ }_{63}$ Oficio del Ministro de la Guerra a la Junta enviádole una exposición del Mariscal de Campo Felipe de Arco Agüero, recibida a través del Capitán General de Andalucia, reclamando contra la orden de 9 de junio para la entrega del arsenal. A. C., t. 38, 476 y 476v. Esta decisión final de la Junta el 5 de junio le advirtió de los inconvenientes y que no lo tuvo en cuenta en la Real orden del 9 . Así, dando el visto bueno para que se hiciera ese momento en que ya se reunian las Cortes, se descargó de responsabilidad. A. C., t. 35, 422 y $422 \mathrm{v}$. sesión de tarde del 5 de julio; Oficio del 8 de julio de la Junta Provisional al Ministro de la Guerra para la entrega del Arsenal de la Carraca una vez reunido el Congreso de los Diputados. A.C., t. $38,477-478$.

${ }^{64}$ En la sesión de tarde del 15 de junio (A. C., t. 35, 314v.; t. 38, 470 y $470 v$.) acordó que los Ministros de Guerra y Marina debían resolver conjuntamente no fuera que el primero hubiera dado órdenes diferentes. El 9 de junio el Ministro de la Guerra daba orden al Capitán general de Andalucía para la devolución del Arsenal en todos los aspectos económico, gubernativo y militar. A. C., t. 38,461 y $461 v$.; t. 35, 342, sesión de mañana del 10 de junio. 
Ningún caso es comparable al del Marqués de las Amarillas, titular de Guerra, ya que los enfrentamientos entre el Gabinete y la Junta parecen simples escaramuzas frente a los mantenidos entre ésta y el Ministro de la Guerra y, aunque no se llegó a una lucha sin cuartel, las relaciones fueron muy difíciles. La razón fundamental de ello parece estar en una concepción completamente divergente sobre el tratamiento que debía darse a un ejército que había propiciado el acceso de ambos al poder. Mientras el Ministro, que detestaba el que los cambios hubiesen llegado de la mano de un ejército rebelde, pretendía que la disciplina se mantuviese en cualquier caso incluso ante medidas, por desagradables que fueran, que él creía necesarias, la Junta trataba de evitar a toda costa el enfrentamiento con un ejército que a partir del 1 de enero había dado, y seguía dando, sobradas muestras de efervescencia política. Otras causas más secundarias vendrían a añadirse a la ya señalada, como puede ser el gran número de oportunidades en que el desacuerdo fue posible gracias a la importancia de la institución castrense, la escasa flexibilidad del Ministro en muchas y reiteradas ocasiones en que creía estar seguro de tener la razón, la seguridad que le daba el hecho de ser el único Ministro llamado por el Rey, y la postura vigilante y tutelar de la Junta respecto a las actividades gubernamentales.

El 10 de abril la Junta recibió de una diputación de vecinos de Madrid la petición de que no se separase del mando interino del Regimiento de Infantería Fernando VII al Brigadier Gálvez y la expresión del disgusto causado en unos y otros por este motivo. Siguiendo su política condescendiente con el ejército indicó al Ministro que, de no haber una razón muy poderosa para hacerlo, sería mejor no variar el mando del Regimiento ${ }^{65}$. La contestación de Amarillas negándose se basó en que, antes de la petición de la oficialidad del Regimiento, ya había sido nombrado para el cargo José María Torrijos y destinado Gálvez a la organización de la Milicia Nacional de Madrid, y que acceder al cambio iria en menoscabo de la reputación de Torrijos y de la disciplina ${ }^{66}$. Con ello Amarillas mantenía su postura.

La Real orden que el 11 de abril partió del Ministerio de la Guerra destituyendo al Marqués de Lazán de la Capitanía General de Aragón, desencadenó uno de los episodios más tensos en la cúpula del poder ${ }^{67}$.

65 Oficio del 10 de abril de la Junta al Ministro de la Guerra sobre la separación del Brigadier Gálvez. A. C., t. 38, 309 y 309v.; t. 35, 134v., sesión de tarde del 10 de abril.

${ }_{66}$ Contestación del 11 de abril del Ministro a la Junta negando la petición de reponer al Brigadier Gálvez en el mando del Regimiento de Infantería Fernando VII, A. C., t. 38, 310-311; t. 35,136 , sesión de mañana del 11 de abril.

${ }^{67}$ Real orden de 11 de abril exonerando de la Capitania General de Aragón al Teniente 
En principio la Junta no puso ninguna objeción a este cambio probablemente por la conducta poco clara del Marqués de Lazán en los días que siguieron en Zaragoza a la proclamación de la Constitución el 5 de marzo y por la actitud arrogante de la Junta de Aragón de la que era Presidente ${ }^{68}$. Pero la alarma cundió entre sus miembros cuando el 21 de abril se presentó el Coronel Francisco Romeo, con un pliego de la Junta de Aragón solicitando la anulación de la Real orden y anunciando que estaban al llegar reclamaciones semejantes del Ayuntamiento de Zaragoza y de varios ciudadanos haciendo constar la inquietud reinante en aquella plaza y guarnición ${ }^{69}$. El Ministro se plegó a los deseos de la Junta "para evitar males mayores, si es que hay alguno mayor que el desdoro de la autoridad real", "aunque S.M. tuvo fundados motivos para tomar esta medida", y decidió que continuase el Marqués de Lazán en el mando militar de Aragón para satisfacción de la Junta que lo comunicó rápidamente a la de Aragón y al Ayuntamiento de Zaragoza atribuyéndose todo el mérito ${ }^{70}$. En los días siguientes a aquella fecha el Ministro de la Guerra tuvo que aguantar en silencio no sólo las grandilocuentes expresiones de agradecimiento dirigidas a la Junta Provisional, sino incluso la acusación de arrancar al Rey el decreto "por sorpresa" por lo que la Junta deberia redoblar la vigilancia de sus Ministros ${ }^{71}$.

El incidente, con ser grave, puesto que se obligaba al Ministro a revocar una Real orden por presiones políticas, no hubiera ido a más a no ser por la torpeza con que el Marqués de Lazán actuó ante la presencia de su

General Marqués de Lazán y nombrando en su lugar al Mariscal de Campo Miguel de Haro, A. C., t. 38, 156 y 156v.; t. 35, 138, sesión de mañana del 12 de abril.

68 Parece que el dia 6 de marzo mantuvo contactos con otras provincias del Norte (Gobernadores de los partidos de la provincia y Capitanes Generales de Navarra y Guipúzcoa) para ver cómo se podía sofocar la "marea revolucionaria". Oficio del Marqués de Lazán, Luis Palafox, al Virrey de Navarra, Conde de Ezpeleta en Francisco EsPOz y Mina. Memorias del General. Madrid, BAE CXLVI, t. I, 236 y 237. Viendo la imposibilidad de éxito de una postura contraria se sumó al carro y se puso a la cabeza de la revolución en Aragón hasta el punto de formar como presidente de la Junta constituida el 7. Diario político de la Junta Gubernativa de Aragón, Zaragoza, Imp. de Francisco Magallón, jueves 30 de marzo de 1820, n. 6. A. C., t. 41, 169-170v. En el oficio del 1 de abril de la Junta de Aragón se desmentía la conducta irregular del Marqués de Lazán, se erigía en defensa frente a facciosos, abusos, etc. y "no permitirá que el Ministerio tome medidas anticonstitucionales". A. C., t. 41,166 y 166v.; t. 35, 106 y 106v., sometida del mañana del 4 de abril.

${ }_{69}$ A. C., t. 38, 157-157v.; t. 35, 171v. y 172, sesión de mañana del 21 de abril.

${ }^{70}$ Exposición de varios ciudadanos de Zaragoza al Rey y representación a la Junta Provisional del Ayuntamiento, ciudadanos y Junta de Zaragoza de 24 y 25 de abril. A. C., t. 41, 175-177v. y 184-188v.; t. 35, 201, sesión de mañana del 28 de abril.

${ }_{71}$ Real orden de 21 de abril para la continuación en el cargo del Marqués de Lazán, A. C., t. 41,180 y $180 v$.; t. 38, 161-162; t. 35, 174, sesión de tarde del 21 de abril. Contestaciones de la Junta Provisional a la de Aragón y al Ayuntamiento de Zaragoza, A.C., t. 41, 182 y 183. 
sustituto, Miguel de Haro, que desconocía las nuevas órdenes, en Zaragoza el 26 de abril. Esgrimiendo, como era habitual en él, razones de orden público, lo envió al Castillo de la Aljaferia "no como arrestado sino por su seguridad". Las noticias que recibió la Junta del propio Miguel de Haro sobre la torpe conducta y las sospechas de anticonstitucionalidad del Marqués, las justificaciones nada convincentes del mismo, el mentís del Jefe Político de Zaragoza en cuanto a alteraciones del orden, la existencia de partidas de paisanos armados y de soldados a las órdenes del Capitán General para servicios especiales, etc. ${ }^{72}$ le llevaron a solicitar del Ministro el 6 de mayo la destitución definitiva del Marqués de Lazán "dada la conducta impolitica y sospechosa", demostrada "después que ella misma pidió su permanencia" ${ }^{73}$. Realmente la conducta del Capitán General de Aragón nunca fue clara y la Junta Provisional cometió el doble error, no reconocido, de menoscabar la autoridad del Ministro de la Guerra y prestar oídos a los cantos de sirena del Marqués de Lazán y sus partidarios. Aunque finalmente rectificó, el daño ya estaba hecho porque su falta de apoyo a la Real orden de 11 de abril siguió abriendo fisuras difícilmente reparables por mucho que el tiempo, que no la Junta, viniera a dar la razón al Marqués de las Amarillas.

Sin embargo, cuando en la medianoche del 16 de mayo recibió el Gobierno una representación en nombre de la sociedad patriótica de Lorencini, que obligó a los Ministros de Gracia y Justicia, Hacienda y Gobernación de la Península a reunirse urgentemente y pedir a la Junta que lo hiciera de inmediato porque así lo exigía "el decoro del Gobierno y de los Ministros y la tranquilidad pública", ésta decidió con toda calma en la mañana del 17 que se procediese legalmente contra los autores del escrito ${ }^{74}$. El contenido de la representación iba dirigido contra el Marqués de las Amarillas, que "no disfrutaba de la confianza pública" ${ }^{75}$, con el pretexto de ser

72 Expediente de los sucesos ocurridos en Zaragoza el 26 de abril con la documentación producida como consecuencia de ellos. A C., t. 38, 182-215.

73 Aconsejaba al mismo tiempo que el medio más oportuno para su separación del mando de la Capitania General era darle orden de presentarse inmediatamente en Madrid y encargar interinamente de aquella Capitanía al General de cuartel en Aragón que se creyese más oportuno. A. C., t. 38, 216 y 216v.; t. 35, 226v. y 227, sesión de tarde del 6 de mayo.

74 Oficio del 16 de mayo de los Ministros Manuel García Herreros, José Canga Argüelles y Antonio Porcel al presidente de la Junta provisional enviando la representación de la Sociedad Patriótica Lorencini. A. C., t. 40, 291-292; t. 35, 261, sesión de mañana del 17 de mayo. Comunicación del 17 de marzo del Ministro de la Gobernación, Antonio Porcel, a la Junta de haber pasado al juez de primera instancia de Madrid el escrito de la Sociedad Patriótica Lorencini para proceder contra sus autores. A. C., t. 38, 225-226; t. 35, 267 y 267v., sesión de tarde del 18 de mayo. Sobre ésta y otras actividades de las sociedades véase, Alberto GIL Novales. Las Sociedades Patrióticas (1820-1823). Madrid, Tecnos, 1975, t. I, 752 pp.

75 Contestación de la Junta Provisional a los Ministros de Gracia y Justicia, Hacienda y Gobernación. A. C., t. 40, 293-294; t. 3, 261 y 262, sesión de mañana del 17 de mayo. 
el responsable de los alborotos ocurridos en Zaragoza el 14 de mayo, relacionados todavia con la destitución del Marqués de Lazán y la disolución de sus partidas ${ }^{76}$. Como se ve, la condescendencia política de la Junta desembocó en una mayor hostilidad contra el Ministro de la Guerra. Pero hay que señalar que, aunque no reconoció políticamente su error (nunca lo hizo, por otra parte), se apresuró a cortar de raíz esta manifestación pública contra el Ministro al que, a pesar de todo, defendió de los ataques que le venían de los sectores más radicales como Juntas y Sociedades patrióticas e, incluso, de compañeros del propio Gabinete. De modo que, cuando la provisional se disolvió, no tuvo que temer su resistencia, como él mismo reconoció ${ }^{77}$, pero tampoco pudo contar con su apoyo en momentos difíciles y, en definitiva, su dimisión, tantas veces presentada anteriormente, fue inevitable.

${ }^{76}$ El parte del 15 de mayo del Jefe Político de Zaragoza, Luis Veyán, y la exposición de la Junta de Aragón del 16, hablan del interto de subversión del orden en Zaragoza en la noche del 14 por parte de los mismos sediciosos que intentaron alterar el orden a la llegada de Miguel de Haro para sustituir al Marqués de Lazán que todavía en esa fecha permanecía en Zaragoza. Los desórdenes fueron fácilmente sofocados con el resultado de un sóloherido y treinta detenidos. Expediente de los sucesos ocurridos en Zaragoza el 14 de mayo, A. C., t. 38, 222-238. Gaceta E., 17 mayo 1820, n. 81, 567 y 568 y Gaceta, 25 mayo 1820, n. 85, 609 y 610 .

77 AmARiLLAS, op. cit., t. II, 129. 